Section Editor

John J. Millichap, MD

Anand Desai, BS

John Stelzer, MS

Sapna Desai

Stephen Berman, MD, $\mathrm{PhD}$

Correspondence to

A. Desai:

AnandDesai@knights.ucf.edu

\title{
Emerging Subspecialties in Neurology:
} Neuro-ophthalmology

Neuro-ophthalmology bridges the gap between 2 distinct yet related specialties: neurology and ophthalmology. Specifically, it focuses on the aspects of the nervous system involved with vision, including the afferent and efferent visual systems. ${ }^{1}$ Using the eye as a lens to view neurologic and systemic disease, neuro-ophthalmologists can identify preliminary signs and symptoms that, if untreated, can result in a myriad of complications due to a wide range of diseases, including optic neuritis, nystagmus, papilledema, diplopia, Horner syndrome, intracranial pressure problems, multiple sclerosis, and many more. ${ }^{2}$ As a result, neuro-ophthalmology focuses on identifying neuroanatomical problems and using this information to determine the etiology of pathologic mechanisms of disease. ${ }^{1}$ The specialty has been described as a rewarding field that combines the direct inspection and surgical skills of ophthalmology with the diagnostic and management aspects of neurology. ${ }^{1,3}$

HISTORICAL DEVELOPMENT The relationship between the eyes and the brain was first proposed by Alemaeon around 2,500 years ago, ${ }^{4}$ but a definitive relationship between the fields of ophthalmology and neurology was not discovered until many years later. Around the year 1000, Alhazen suggested that images created in the lens travel through hollow optic nerves to the chiasm and brain, proposing the first ideas congruent with the field of neuro-ophthalmology. ${ }^{5}$ Neetens, ${ }^{5}$ however, states that "the definite birth of neuroophthalmology" occurred in the 1400s, when Leonardo da Vinci expanded on Alhazen's ideas by suggesting that visual stimuli travel to the areas of the brain involved in representation, reasoning, and memory. From this point, the field of neuro-ophthalmology continued to develop with increasing speed. Kepler (1571-1630) tried to determine if the eyes or brain are used for sight, and at a similar time Descartes (1596-1650) began to consider the relationship between the brain and vision, and he accomplished this by recognizing that the retina connects visual stimuli to the brain.

While the connection between the brain and eyes was strengthening, the relationship between pathologic neuroanatomy and functional abnormalities had yet to be fully elucidated. William Hammond, a pioneer in the field of neurology, began illuminating the connection between the brain and eyes in his book Treatise on Diseases of the Nervous System (1871), which was the first American textbook of neurology. Similarly, by studying Civil War patients with brain lesions, Silas Mitchell identified relationships between brain lesion location and functional deficits. This work was presented in his study Injuries of Nerves (1872), which became an important manuscript in the field of neuro-ophthalmology. In December 1874, the American Neurological Association was founded by a committee of physicians led by William Hammond. ${ }^{6}$

In addition to the early pioneers of neuroophthalmology, several other prominent physicians contributed to the rapid development of modern neuro-ophthalmology at the turn of the 20th century. Hughlings Jackson (1835-1909) was the first to regularly use the ophthalmoscope to check the fundus; Jonathan Hutchinson (1828-1913) solidified the relationship between neuro-ophthalmology and ophthalmology by identifying classic signs and symptoms of ocular diseases ${ }^{5}$; and Frank Walsh (18951979), regarded as the founder of modern neuroophthalmology, created the specific medical niche of neuro-ophthalmology due to the depth of his experience with a large number of patients.

Starting in the 1950s, surgical and imaging techniques became increasingly important in the evolution of the field, and the field of neuro-ophthalmology has since grown rapidly. In 1976, the International Neuro-Ophthalmological Society was formed, and the North American Neuro-Ophthalmology Society was formed in $1980 .{ }^{4,7}$

FELLOWSHIPS AND TRAINING Neuro-ophthalmology fellowships can fall under either a neurology or ophthalmology department and are an option for either neurology or ophthalmology residents. While the Accreditation Council for Graduate Medical Education does not play a role in neuro-ophthalmology

From the University of Central Florida College of Medicine (A.D., J.S., S.B.), Orlando; and University of Virginia College of Arts and Sciences (S.D.), Charlottesville.

Go to Neurology.org for full disclosures. Funding information and disclosures deemed relevant by the authors, if any, are provided at the end of the article. 
fellowships, the North American Neuro-Ophthalmology Society (NANOS), which is composed of 508 members, ${ }^{7}$ and the Association of University Professors in Ophthalmology (AUPO) Fellowship Compliance Committee (FCC) have created specific guidelines for neuro-ophthalmology fellowships. While neuroophthalmology fellowships are not required to follow guidelines created by the AUPO FCC, adherence to the established guidelines is strongly supported by NANOS.

No match process exists for neuro-ophthalmology fellowships due to the logistical challenges between neurology and ophthalmology fellowships and the relatively small number of applicants. Consequently, the San Francisco match provides a separate centralized application service, unrelated to the match, for prospective neuro-ophthalmology fellows that works on a firstcome-first-served basis. Nevertheless, the decision to become part of the San Francisco match is still considered on an annual basis. ${ }^{8}$ As there is no match process, it is important for applicants to apply early, as neuroophthalmology programs can fill their spots years in advance. ${ }^{7}$ Application deadlines may also vary, so it is important for prospective fellows to contact programs of interest to inquire about deadlines and application requirements. Additional application requirements

\begin{tabular}{ll|}
\hline Table & \multicolumn{1}{c}{ AUPO-FCC-compliant programs and AUPO-FCC-noncompliant programs ${ }^{7}$} \\
AUPO-FCC-compliant programs & AUPO-FCC-noncompliant programs \\
Baylor College of Medicine & Michigan State University \\
Dean McGee Eye Institute & University of British Columbia \\
Emory University & University of Pittsburgh \\
Harvard Medical School Program & University of Toronto \\
Illinois Eye and Ear Infirmary (University & Wills Eye Hospital (Thomas Jefferson \\
of Illinois at Chicago) & University) \\
New York Eye \& Ear Infirmary of Mount Sinai & \\
NYU Langone Medical Center & \\
UCLA Doheny Eye Center & \\
University of Alabama at Birmingham & \\
University of lowa & \\
University of Miami & \\
University of Michigan & \\
University of Minnesota & \\
University of Pennsylvania & \\
University of Tennessee Health Science Center & \\
University of Texas Southwestern Medical & \\
Center & \\
University of Utah Moran Eye Center & \\
Weill Cornell Medical College & \\
Wilmer Eye Institute (Johns Hopkins University) & \\
\hline
\end{tabular}

Abbreviations: AUPO $=$ Association of University Professors in Ophthalmology; FCC = Fellowship Compliance Committee. often include a curriculum vitae, personal statement, and letters of recommendation. ${ }^{8}$ Experience working with a neuro-ophthalmologist, research experience, and additional activities that demonstrate a passion for the field during residency will also help aspiring neuro-ophthalmologists obtain a fellowship. For more information about individual fellowship program requirements, please see the link included in the references. ${ }^{7}$ This Web page contains links to detailed tables outlining contact information and application information for both AUPO-FCC-compliant programs and non-AUPO-FCC-compliant programs. Between compliant and noncompliant programs, there are a total of 24 neuro-ophthalmology academic centers (table). Neuro-ophthalmology program faculty at individual institutions may include neurologists, ophthalmologists, neuro-ophthalmologists, or any combination of these. $^{7}$

All AUPO-FCC-certified programs require predetermined amounts of exposure to afferent visual pathway disorders (e.g., optic neuritis, papilledema, pseudotumor cerebri), efferent pathways disorders (e.g., nystagmus, pupil and lid disorders), and systemic neuro-ophthalmic disorders (e.g., myasthenia gravis, multiple sclerosis), but the specific curricula of the programs can still vary significantly. Experience in surgery is not required by the AUPO FCC, but surgical involvement may be required or offered by certain programs. AUPO FCC certification requires that fellows are provided with the opportunity to take part in research if interested, and as such, almost all programs strongly encourage or require research participation during fellowship training. The opportunity to teach residents is integrated into the curricula of some neuro-ophthalmology fellowships as well. Most fellowship programs offer funding for 1 or 2 fellows and are predominately 1 year in length, but some programs may offer longer alternatives.

\section{CAREER PROSPECTS AND CONCERNS Reports}

have demonstrated that there is a shortage of neuroophthalmologists. ${ }^{9}$ In the United States in 2008, it was estimated that we would need $25 \%$ more neuroophthalmologists to fulfill the needs of our population. Moreover, the shortage of neuro-ophthalmologists was anticipated to continue to grow, ${ }^{9}$ and it is likely that patient care will be affected if this shortage is not addressed. It has been suggested that the number of neuro-ophthalmologists may be decreasing, not because of a lack of interest in the specialty, but rather due to perceptions of undercompensation, the difficulty of the field, and a lack of jobs. ${ }^{3,9}$ Fortunately, however, these problems have been recognized, and multiple solutions to improve compensation and interest in the field have been suggested and implemented. Some solutions can be considered and 
utilized during residency, whereas others are more applicable during and after a neuro-ophthalmology fellowship.?

Solutions to address the neuro-ophthalmologist shortage, such as strategies to increase resident interest in the field, present several opportunities that residents can take advantage of. NANOS has started offering travel grants to encourage interested residents to attend the annual NANOS meeting. They also provide research grants to residents interested in the field. Moreover, NANOS suggests that potential neuro-ophthalmologists consider practicing neuroophthalmology in conjunction with another specialty to help provide additional revenue. ${ }^{9}$

Solutions that aim to improve the quality of the field for practicing neuro-ophthalmologists also exist. Due to the complexity of many neuroophthalmologic diseases, patient visits are often lengthy, ${ }^{10}$ resulting in decreased revenue. Consequently, strategies to decrease visit time have been suggested. Increasing financial compensation can also be accomplished by redistributing hospital income to provide increased funds for neuro-ophthalmologists and providing neuro-ophthalmologists additional income for services such as teaching.'

As a result of both the shortage of neuroophthalmologists and the concerns regarding undercompensation, neuro-ophthalmologists are highly valued members within health care. Neuro-ophthalmologists often provide the most economical way to care for complex and time-consuming cases, as they allow ophthalmologists with other specialties to partake in cases that generate more income. This increases department throughput and could help resolve undercompensation issues, if used in combination with suggested neuroophthalmologic reforms that redistribute income. Moreover, presumably because of their detailed knowledge of multiple fields, neuro-ophthalmologists are also highly valued in hospital settings because they often contribute substantially to teaching. ${ }^{9}$

Spitze et al. ${ }^{3}$ also report positive accounts of the neuro-ophthalmology specialty due to a variety of factors, including the ability to see a variety of conditions that utilize knowledge from multiple specialties, practice both medicine and surgery, and diagnose complex and challenging cases. These benefits draw individuals to the field each year, and it is reasonable to conclude that implementation of reforms that address neuro-ophthalmologic concerns will continue to stimulate growth of the field.

\section{AUTHOR CONTRIBUTIONS}

Anand Desai: drafting and revising the manuscript. John Stelzer: drafting and revising the manuscript. Sapna Desai: drafting and revising the manuscript. Stephen Berman: revising the manuscript.

\section{STUDY FUNDING}

No targeted funding reported.

\section{DISCLOSURE}

A. Desai serves as an editor for The Medical Student Press Journal. J. Stelzer and S. Desai report no disclosures relevant to the manuscript. S. Berman was a Chief Editor and Contributing Editor for Neurology for Medscape (EMedicine) and is a coinvestigator on a grant (1525990) from the National Science Foundation that runs from 2015 to 2017. Go to Neurology.org for full disclosures.

\section{REFERENCES}

1. Biousse V, Newman NJ. Neuro-ophthalmology Illustrated. Stuttgart, Germany: Thieme; 2009.

2. Palau AE, Morgan ML, Yalammanchili S, Lee AG. Neuroophthalmology annual review. Asia Pac J Ophthalmol 2014;3:104-125.

3. Spitze A, Al-Zubidi N, Lam P, Yalamanchili S, Lee AG. Neuro-ophthalmology as a career. Indian $\mathrm{J}$ Ophthalmol 2014;62:1013.

4. Huber A. The history of neuro-ophthalmology in Europe. Neuro-ophthalmology 1999;21:117-121.

5. Neetens A. Evolutionary history of neuro-ophthalmology. Neuro-ophthalmology 2000;23:95-126.

6. American Neurological Association. Historical overview. Available at: http://myana.org/historical-overview. Accessed December 23, 2015.

7. North American Neuro-Ophthalmology Society. NANOS Neuro-Ophthalmology Fellowships and the Value of AUPO FCC Compliance. Available at: http://www.nanosweb.org/ i4a/pages/index.cfm?pageid=3371. Accessed August 1, 2015.

8. Lee AG, Keltner JL. Fellowship training in neuroophthalmology in the United States. J Neuroophthalmol 2015;35:1-2

9. Frohman LP. The human resource crisis in neuroophthalmology. J Neuroophthalmol 2008;28:231-234.

10. McDonnell PJ. Is neuro-ophthalmology in jeopardy? Ophthalmol Times 2004;29:4. 


\section{Neurology}

\section{Emerging Subspecialties in Neurology: Neuro-ophthalmology \\ Anand Desai, John Stelzer, Sapna Desai, et al. \\ Neurology 2016;86;e222-e224 \\ DOI 10.1212/WNL.0000000000002691}

This information is current as of May 23, 2016

\section{Updated Information \& Services}

References

Citations

Subspecialty Collections

Permissions \& Licensing

Reprints including high resolution figures, can be found at: http://n.neurology.org/content/86/21/e222.full

This article cites 7 articles, 0 of which you can access for free at: http://n.neurology.org/content/86/21/e222.full\#ref-list-1

This article has been cited by 1 HighWire-hosted articles: http://n.neurology.org/content/86/21/e222.full\#\#otherarticles

This article, along with others on similar topics, appears in the following collection(s):

\section{All Neuro-ophthalmology}

http://n.neurology.org/cgi/collection/all_neuroophthalmology

Other Education

http://n.neurology.org/cgi/collection/other_education

Information about reproducing this article in parts (figures,tables) or in its entirety can be found online at:

http://www.neurology.org/about/about_the_journal\#permissions

Information about ordering reprints can be found online:

http://n.neurology.org/subscribers/advertise

Neurology ${ }^{\circledR}$ is the official journal of the American Academy of Neurology. Published continuously since 1951, it is now a weekly with 48 issues per year. Copyright @ 2016 American Academy of Neurology. All rights reserved. Print ISSN: 0028-3878. Online ISSN: 1526-632X.

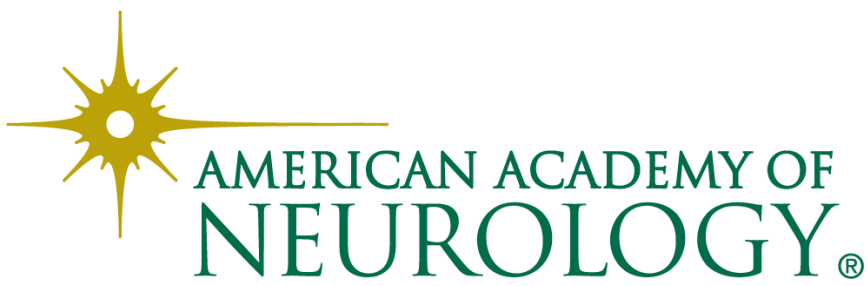

